\title{
Corporate Governance and Ethical Compliance-Deriving Values from Indian Mythology
}

\author{
Gourav Vallabh1*, Garima Dadhich² \\ ${ }^{1}$ Finance Area, XLRI Xavier School of Management, Jamshedpur, India \\ ${ }^{2}$ Indian Institute of Corporate Affairs, Manesar, India \\ Email: ^gvallabh@xlri.ac.in
}

How to cite this paper: Vallabh, G. and Dadhich, G. (2016) Corporate Governance and Ethical Compliance-Deriving Values from Indian Mythology. Theoretical Economics Letters, 6, 1128-1144.

http://dx.doi.org/10.4236/tel.2016.65108

Received: September 23, 2016

Accepted: October 17, 2016

Published: October 20, 2016

Copyright $\odot 2016$ by authors and Scientific Research Publishing Inc. This work is licensed under the Creative Commons Attribution International License (CC BY 4.0).

http://creativecommons.org/licenses/by/4.0/ (c) (i) Open Access

\section{Abstract}

Corporation is the most important part of value chain of growth for any nation, being developed or developing. These corporation acts through the board of directors elected by management team and shareholders. With markets expanding beyond domestic boundaries, globalization has found new space, first in vision and then very swiftly in mission statements of corporates. By these expanding organizations, not only the balance sheets of these new global corporates have become rich but also brought citizens from every corner of world to contribute and become part either as employees or as valuable stakeholders. This wave of globalization led to the amalgamation of different cultures under ambit of leadership which itself varied in terms of cultures and richness of moral values. For such originations and multinational corporations, the whole world is one market, both for their input requirement and output sell. The phrase Vasudhaiva Kutumbakam from Maha Upanishad [1] rightly suits the new culture of such global organizations. While competing in global market, they do require inheriting, replicating and practicing age old principles of $\mathrm{Va}$ sudhaiva Kutumbakam, ensuring competition in healthy sense while maintaining ethics and integrity in entire range of decision making process. This paper attempts to review the age old mythological principle of Vasudhaiva Kutumbakam to inherit leadership traits required in tough competitive market and incorporate an ethical dimension into the values, they stress upon. This paper will also attempt to review the various models like Utilitarian model, moral rights model and Justice model and draw a fine analogy between Indian mythological principle and corporate governance. The paper establishes the growing consensus that effective corporate governance, just like human behaviour, is and ought to be firmly anchored in assimilated values rather than cosmetic compliances which aims to reassure stakeholders about the company's exposure to various risks, mostly in reference to decision making proc- 
ess. This was achieved by analysing and interpretation of various available research to help understand good corporate governance from Indian culture and traditions.

\section{Keywords}

Board of Directors, Corporate Governance Framework, Ethical Corporate Governance, Leadership Traits

\section{Introduction}

"Business must harness the power of ethics which is assuming a new level of importance and Power"

-James Joseph

Corporates are under fire. There is perceived immense pressure on corporates, to raise funds as investment promising higher returns, to go through litmus test for the decision and growth model they undertake and almost every day bestowing trust among all investors and stakeholders including minority ones. To succeed in today's business, ability to accomplish the expectations of stakeholders plays key role. In current global competitive environment, corporates require huge funds. There is ample of public funds available, provided the leadership present a transparent image of their pious intent of handling business with passion and exemplary expectation.

In today's changing business environment with new challenges in the hemisphere for exhibiting new values requires new leadership which can be counted in terms of spiritual leadership. Indian mythology goes ahead with teaching of Vasudhaiva Kutumbakam and doing business for benefits of all with no negative externalities. Vasudhaiva Kutumbakam is a philosophy that inculcates the spiritual leadership in decision making body and stresses on building an understanding that the whole world is one family and thus no action of business should negatively impact any quarter of this global family. This philosophy guides the leaders handling realms of business to be competitive but be ethical in their behaviour. The new dimensions of business ethics deal with ethical rules and principles necessary for successful business. While dealing with day to day decision making process in board room, the leadership goes through various phases where they required to exhibit ethical and moral responsibility towards the outcome of their decision and inculcate the compliance in every management functioning from top to bottom.

This paper attempts to correlate business ethics with functional behaviour of the corporations. Ethics matters in business because all stakeholders stand to gain when organizations, groups, and individuals seek to do the right thing. In achieving good governance, board of director acts as supreme authority to oversee the ethical performance and to display efficient leadership traits in the interest of organisation. Companies should take decisions for profit maximisation within ethical boundary. The governance system of a company is based on three things, ethics, transparency and ac- 
countability thus effective corporate governance can only be achieved by agreeing to a set of principles, values and best practices derived from Indian mythology.

\section{Literature Review}

Corporate governance covers a large number of distinct concepts and phenomenon as we notice from the definition adopted by Organization for Economic Cooperation and Development (OECD) - “Corporate governance is the system by which business corporations are directed and controlled. The corporate governance structure specifies the distribution of rights and responsibilities among different participants in the corporation, such as, the board, managers, shareholders and other stakeholders and spells out the rules and procedures for making decisions in corporate affairs. By doing this, it also provides the structure through which the company objectives are set and the means of attaining those objectives and monitoring performance [2]". Upon deriving the in-depth understanding from this definition, it is well evident that the Corporate Governance principles stresses the importance of relationship of a company to its various shareholders and stakeholders. This "relationship", gets strengthened from promotion of transparency, fairness and accountability in actions by giving "governing" mechanism to board and decision making body of a company, such that to ensure that all decision been taken are consistent with the broader interest of not only key stakeholders groups but include minority ones as well. This "relation" of enhanced accountability, deemed necessary by governing framework of Corporate Governance and requires companies and its operating body to get aligned with the ethical obedience and alignment for the un-shattered interest of all stakeholders.

Following the traditional understanding, the corporate governance is defined as leadership and control of a firm with the aim of securing the long term survival and viability of that firm Shleifer et al. 1986 [3]. But recent business scandals and financial crises continue to provide ample cause of concern and have fuelled interest in the ethical aspect of corporate governance Brink A. 2011 [4]. Weiss 2009 [5] notes that just like every human community has its own value system, every organization has its own value system too. These values enable prioritization of objectives and the modes of attaining the same.

The frauds of Satyam, WorldCom and Enron are most discussed cases in corporate governance failure. But this never ending list of breach of trust between companies and its stakeholders, dates long back in history with first known corporate collapse of Medici Bank in 1494 and Mississippi Company in 1720. After years of diligent scientific efforts aimed at finding satisfactory, conclusive answer to this fundamental problem of failure of corporates to gain and retain trust of investors, it was found that the major reason behind is misalignment between business economical model of growth and behavioural ethical leadership of management. Many hypotheses are then developed and tested to establish the relationship between the two and invariably, results of all such conducted studies shows that most important requirement in business is building trust and which is directly proportional to transparent decision making and which yet again 
in turn can be inculcated in behavioural compliance of corporates by building ethical behavioural in organizations.

Many companies in the US have adopted legal compliance mechanisms which address ethics or conduct issues in formal documents (Weaver et al 1999) [6], but much of this activity has been attributed to the 1991 U.S. Sentencing Commission's Guidelines for organizational defendants which prescribe more lenient sentences and fines to companies that have taken measures to prevent employee misconduct (Metzger et al, 1994 and Paine, 1996) [7] [8]. Looking this in framework of ethical compliance required by companies under constitutional mandates of various countries, the most prominent issue in relationship of company with its stakeholders involves the continuous process of building trust and accountability.

Harshbarger et al. 2004 [9] point out that while many of the governance issues that organizations face are not new, the environment in which they confront them is more challenging than ever: State and Federal law enforcement have applied significantly increased resources and a more aggressive philosophy toward confrontation of governance lapses; the media spotlight has increased awareness among those constituents directly affected as well as the business community as a whole; shareholder proposals are taken more seriously; and the judiciary has demonstrated its willingness for a more stringent definition of good faith. As well, there are a number of factors that have brought ethical issues into sharper focus, including globalization, technology and rising competition. Van Beek et al. 2004 [10] also note the ability to deliver a professional service will necessarily take place in an environment in which there is an increasing tendency towards individuality, while society as a whole becomes more global.

The new realities of corporate governance show that no entity or agent is immune from fraudulent practices and have altered the way companies operate; they have redefined the baseline for what is considered prudent conduct for businesses and executives (Dandino, 2004) [11]. A stark and complex shift has occurred in how organizations must understand themselves in relation to a wide variety of both local and global stakeholders (Amato et al., 2009) [12].

To be as simplistic as possible, while defining corporate governance, it is nothing but the set of processes, customs, policies, laws and institutions affecting the way a corporate is directed, administered or controlled and hence it lays down the basic framework of governance referring various required mechanisms, processes, and relations to direct and ensure optimal performance of the enterprise. While performing these actions from top to bottom of origination, they do require to inherit and perpetually exhibit the principles of Vasudhaiva Kutumbakam and hence laid down the ethical moralities to follow in Kali Yuga as was done in Satya Yuga, Treta Yuga and Dvapara Yuga. The strong ethical value system followed has survived the most catastrophe, be it economical or natural disaster.

\section{Theoretical Framework}

The word "Governance" or "Sashan" in hindi, is not a new term coined by todays" 
corporates but deciphers through development of civilization since beginning of human race. In ancient India, there were many forms of governance in different periods spread across geographies and regions. Even within a given territory there were many kingdoms with different ways of governance. Basically "Governance" was the directives through which the king or the authority tried to control the administration. In modern business world, the word "Governance" is termed as "Corporate Governance" which is "the system by which companies are directed and controlled" (Cadbury Committee, 1992). It includes the relationships among the many stakeholders involved and the goals for which the corporation is established and been governed. In contemporary business corporations, the main external stakeholder groups are shareholders, debtors, creditors, suppliers, customers and communities affected by the corporation's activities. Internal stakeholders are the board of directors, executives and other employees. An ideal corporate governance system guarantees that an enterprise is directed and controlled in a responsible, professional and transparent manner spin in ethical moral framework with the purpose of safeguarding its long term success and sustainability. It is intended to increase the confidence of various stakeholders.

The success of business lies in its positive reflection in terms of brand building and carrying image in society as an organization which metaphors for the upliftment of society creating positive externality. Off course they required to be competitive, but sooner or later, there is drastic change in the corporate mind set from only being "SelfCentric" to thinking of world as one family and hence realizing the principles of "Vasudhaiva Kutumbakam". This behavioural change from self-centric to real global is outcome of perceived understanding that the continued focus on legal compliance through regulatory and institutional reform cannot ensure justice and inspire organizational excellence. An ethics, by virtue promotes and builds integrity, capacity in recognizing that those whose business it is to govern ought to aspire toward becoming virtuous. Ethical compliances motivate accountability, responsiveness, responsibility, and transparency in the practice of good governance.

Many issues of corporate governance circumfenced around integration of different legitimate values. Though return on equity is important, equally important is conducting business without compromising on ethical principles, which are building block of any business having got invested by people. Shareholders activism is valuable, but they must also be willing to let management discharge their duties. The scope and complexity of corporate governance mechanisms have been steadily increasing over the past decade and include issues such as risk management, the role of government including its role in dealing with systemic risk, executive compensation, proposals to improve the professionalism and diligence of boards and board committees, shareholders' activism including shareholder proxy access and disclosures etc.

With increasing competition and insatiable desire of organizations for profits the employees are put under immense pressure to perform. The objective of employees remains only how to increase profits and make money resulting in detachment and dissatisfaction from work seeding non ethical behaviour. The short term gains might be 
achieved, but the long term goal of sustainability is brought at serous stack. In age of information technology, as new news of non-ethical behaviour spreads like a fire in the jungle which ultimately diminished brand value of corporations. History has numerous examples of scandals where such organization could not come back to old way of function, once defamed on account of non-ethical behaviour. Thus, the new approach required to have ethical integrity and still be ahead of competition in returning returns on investors" investment.

\section{Methodology}

For the purpose of research internet sources and various Libraries across the country has been used as a primary source. As far as secondary sources are concerned, the values derived from Indian mythology, the policies made by the Government to regulate various corporate governance issues such as concept of independent directors, disclosure, class action suits, related party transactions, whistle blower mechanism have been read and analyzed with the concept of Vasudhaiva Kutumbakam. Other than these, various articles and research papers of several scholars have been cited in this paper wherever appropriate.

Considering the primary and the secondary sources of research, the method of the research done is purely "Doctrinal Method". The study is analytical and descriptive in nature which is mostly drawn from the secondary sources and comparative analysis pertaining to the corporate governance framework with mythological values and ethics. The authors have analysed and interpreted the available literature in the field of corporate governance keeping in view the shift in focus of the corporate governance debate from shareholder theory to stakeholder theory. The main objective of the research is to establish that good governance and ethics (derived from Indian mythology) are so intervened that achieving one at the cost of other is unimaginable and ethics deliver improved living standards for human beings and enhance value for all stakeholders-be it corporate, society or the nation.

\section{Result and Analysis}

Ethics which is branch of philosophy and is considered as normative science in literature studies because it is concerned with the norms of human conduct, is basically the conception of right and wrong behaviour. It helps corporates identifying and judging when their actions are moral and immoral. While defining the business, the true definition lies in its main objectives of maximizing the returns. Clubbing the business in line with ethical principles, gives rise to Ethical Corporate Governance which is the recent buzzword. Recent years have seen the exponential increase in its growth and the level of effort been put on research signifying importance of Ethical Corporate Governance. The demand of improvements in Ethical Corporate Governance practice is being orchestrated at a global level, inducing International bodies such as OECD (Organization for Economic Development) to develop and increase its level of effort towards internationally acceptable standards of Corporate Governance. 
While every company ponders and attempts to raise confidence in its global community, on following a path of Ethical Corporate Governance, but what remains unanswered is accountability of proclamation and how to ensure global investors and stakeholders that corporates are practicing, what they preaching. As elaborated above, Ethical Corporate Governance refers to the processes and policies that a company has in place to deal with issues concerning how it is administered and conducts day to day business.

While Corporate Governance is a multi-faceted subject with many layers of complexity, an important part of Ethical Corporate Governance deals with ensuring accountability, fiduciary duty and mechanisms of auditing and control with ethical compliance, without subsidizing the primary objective of creating product and service to generate profit, but to keep the intention more balanced with controls that ensure, a company pursues profit without crossing over the line into the realms of unethical behaviour. Maintaining these balances requires trade-offs, but this in positive integrity side. Corporate ethics and shareholder desires for profitability are not always aligned, and it is the responsibility of executive management to ensure ethics supersede profitability. For example, before the collapse of Enron, the company and its associated traders are believed to have artificially inflated the price of energy in certain US states, thus increasing their profit margins. While this action alone was not enough to cause the company to collapse it was a clear indication that internal controls had failed, which of course meant that other much larger abuses were possible, which eventually lead to the downfall of the company. Managers are the primary decision makers, and therefore must hold themselves accountable for the way in which a business operates and affects stakeholders, shareholders, employees, and the community at large.

All such incidents of breaching the confidence of investors, turned investors to be more ethical investors and start looking for those originations which scales high on ethical compliance. Ethical investors want to ensure that corporations are being honest and transparent, and that management isn't looking out for its own interests to the detriment of others. With growing need of competition, many companies do start recognizing that to encourage positive behaviours and repeat business with their customers, they ought to undertake their business in the "right way". Companies therefore draw up their values, embed them with their employees and monitor that they do comply. The value espoused include for example integrity, honesty and openness in terms of decision taken while entering a particular segment of market of favouring one decision over the others by the board of governance. This not only limited up to the board decision but drills down to their employees. This calls for an enlightened investing community and strict regulatory regimes to protect the rights of the investors and companies to improve productivity and profitability without recourse to any means which would offend the moral, ethical and regulatory framework of business (Nainawat et al. 2013) [13]. Global economic integration has been a driving force behind the rapid progress of developing and disseminating good Corporate Governance practices and standards. Investors, regulators, shareholders, directors, executives, and the media have all played 
important roles in this changed process, especially within the context of emerging markets.

Ethical corporate governance translates to a kind of applied ethics. The term ethics has its origin from the Greek word "ethos', which means character or custom-the distinguishing character, sentiment, moral nature, or guiding beliefs of a person, group, or institution. The unprecedented financial crises of global scale were very evidently linked to noncompliance on ethics and laxity of corporate governance, which we can say a substance failure of ethical corporate governance. It is increasingly emerging not only as a tool that increases efficiency but also improves access to capital and ensures sustainability. Trust is at the heart of good governance, and good governance promotes sustainable business growth in both private and public corporate sectors, numerous studies by international development organizations have concluded that even though corrupt practices may offer short-term economic benefits, there is a direct correlation between unchecked corruption and stifled development over the long term. Building an effective ethics management system is an ongoing effort, not a one-time project [14]. Even in countries with well-developed economies and government institutions, ethics management systems undergo frequent revisions. For example, at the federal, state, and local government levels in the United States, ethics reform is a continuous process. The current generation of federal ethics measures includes the Ethics Reform Act of 1989; the Honest and Open Government Act of 2007; various presidential memoranda on pay freezes, transparency, and open government; and a recent Executive Order on Presidential Records.

The history of effective Corporate Governance is not a new concept and this can be traced back to Ancient period. Lot of evidences, scriptures, and religious test give reference to the existence of effective corporate governance practiced during our ancient times. In current scenario, corporate governance is talked more from the point of business but in Ancient India, it was about over all administration of state. It talks about how the king used to manage his responsibilities through effective Governance. Manu and Kautilya, the ancient Indian thinkers have given us their rich political and administrative ideas and policies. The roots of these policies lies on ethics as basic foundation element. Where Manu-Smriti upon translation from Sanskrit to English by Sir William Jones in 1794 went to formulating the Hindu Law, the Kautilya Arthasastra helped to be a kingmaker, almost more than two thousand years back and enabled the inception of Gupta Dynasty. Manu-Smriti is based on structures of Dharma (synonym of Ethics) in every action. Herein begins the relevance of studying the Arthasastra and Manu-Smriti. They demonstrated an extremely vital imperative; governance, polity, politics and progress has to be based out of trust and ethics and linked to the welfare of society, bestowing upon the principle of "Vasudhaiva Kutumbakam".

Teachings of ancient Scriptures like Vedas, Upnishads, Bhagavad Geeta, ManuSmriti, Arthasastra, etc., all indicates towards ethical and spiritual frameworks of continuous sustainability. This framework is essential for the functioning of business bodies. All these scriptures stress on creating an environment of trust in those who serves 
you or been served by you. It is quite evident that the failures of many organizations in recent past is due to "substance" failure in creating sustainable business practices because they lack morality or fail to make any ethical consideration while making any business transition. Most of the decisions are based out on element of "Lobh" as mentioned in Manu-Smriti. What happened in sub-prime crisis or corporate scams in corporate America can be attributed to various economic reasons, but the primary reason was wrong management of day to day affairs and laxity in decision making process keeping customer trust as central. One of the important areas in corporate governance is decision making. A collective decision making is what it is linked out today and such decision should be taken keeping in mind not only to help the promoters and owners but also to benefit minority shareholders. In Mauryan and Gupta period also the major decision relating to welfare of the kingdom was taken on collective basis. Each of district and provincial heads were involved and consulted before taking any decision at central level. This pattern was followed, to ensure that collective decision making body practices and exhibits more ethical pattern compared to an individual.

"It is not enough to do well; it must also do good, But in order to 'do good', a business must first 'do well'”-Pearce et al., 2010 [15].

He further stated that-

"...if we want to know what business is, we have to start with its purpose. And the purpose must lie outside the business itself. In fact, it must lie in society, since a business enterprise is an organ of society. There is only one foundation of a business and keeps it in existence. He alone gives employment. And it is to supply the customer that society entrusts wealth-producing resources to the business enterprise...."

Whenever an institution malfunctions as consistently as boards of directors have in nearly every major fiasco of the last forty or fifty years, it is futile to blame men. It is the institution that malfunctions (Pearce et al., 2010).

This signifies the importance of Ethical Corporate Governance. The intention on each corporate governing law is to build upon the trust by the ethical conduct of top most decision making body and inculcating this culture in the bottommost layer of organisation chain.

Practice of Ethical Corporate Governance, fosters a sense of trust among all stakeholders and they feel less stressed while investing money. Once the trust is established, corporates ought to follow the very stringently all ways and means to maintain the trust and this brings out the significance of strictly following the corporate governance norms. Ethical Morality brings out the inner voice of the person serving in board and responsible for decision making authority on behalf of stakeholders. Every person has his own dream and associated personal goals which sometime leads to undermining the broader objectives of an organisation and its goals. This conflict of interest also becomes the root cause of failure of organization [16].

The management and board are required to respond in very critical situation while finding out the absolute right and absolute wrong, and that's where the substance of ethics and corporate norms required to be followed helps them to come out of this de- 
ontologist situation. Literatures defines Deontological ethics or deontology is the normative ethical position that judges the morality of an action based on the action's adherence to a rules. It is sometimes described as "duty" or "obligation" or "rule" based ethics, because rules "attach you to your duty". The genesis of framing and binding the corporates in the framework of corporate governance pedigrees out from this basic principle of ethical morality. Corporate governance norms put a rider on riding behind the motives of profit maximization by deciding right and wrong depending upon the situation. The ethics coupled with the norms of doing business rightly helps board and management to come out of this teleological syndrome. This is how the ethical norms together with well framed corporate governance norms helps organization to enrich the trust of investors and achieve their ultimate goal of maximization of profit without creating any negative externality from their decisions.

The objective function of a business this can be defined as:

$$
F(\mathrm{x})=\max f(\text { profit })+\min f(\text { negative externality })
$$

Subject to adherence of ethical principles derived from Deontological thinking and corporate governance norms.

The main function $F(\mathrm{x})$ can be defined as principle of growth for any business. This framework of maximizing $F(\mathrm{x})$ helps those making reasonable and acceptable decisions because this is aligned to the stakeholders" organization and society. Ancient Hindu Principles provided rulers and business communities to get aligned to model behaviour which is governed by four behavioural perspectives. The Manu-Smriti defines them as Individual behaviour, societal behaviour, organizational behaviour and lastly all encompassed in broader umbrella of Legal undertaking. This body of decision making is been followed in current corporate governance norms which attempts binding the Individual, societal and organizational behaviour under legal umbrella of norms defined as Corporate Governance Norms. Table 1 given below attempts to establish the relational similarities of four behavioural perspective between Manu-Smriti based behavioural system doctrine and modern corporate Governance Framework.

While understanding the model and genesis of Corporate Governance Norms, the necessity of ethical intent is central building block. While ethical behaviour is well understood through three main models namely, Utilitarian Model, Moral Rights Model, and Justice Model, the same helps in building framework for corporate governance. In terms of corporate governance model framework, the utilitarian approach defines the ethical action or lookout in decision making where actions are intended to produce the greatest good and does no harm to any stakeholder including minority. This mandates all employees to be responsible for their decision and should continuously strive to increase the companies/investor's profit/margin. Mathematically this can be understood as following function:

$$
\begin{aligned}
F(\mathrm{x})= & \max f(\text { increase the good done })+\min f(\text { reduce the harm done }) \\
= & \max f(\text { investors' return of investment })+\max f(\text { positive externality }) \\
& +\min f(\text { negative externality })+\min f(\text { conflict of interest })
\end{aligned}
$$


Table 1. Manu-Smriti Doctrine and Corporate Governance Frameworks on various behavioural perspectives.

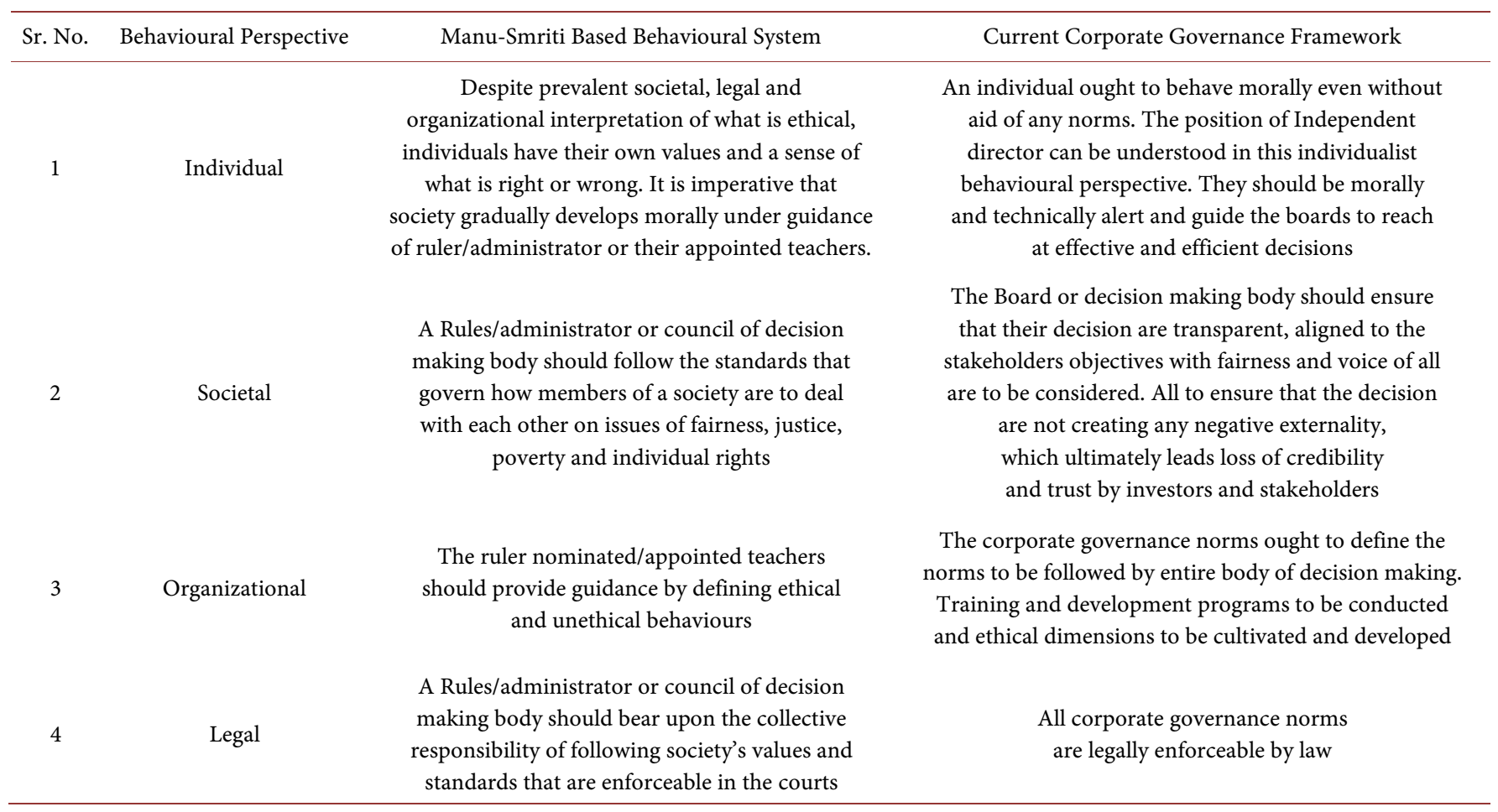

This ethical model prescribes corporates to establish organizational goals focussing on maximizing the returns in competitive market environment as profits are seen as reward for satisfying customer. This again by keeping arm's length distance avoiding principal-agent conflict which is yet again intended through corporate governance norm.

The another model of ethical standard is the "Moral Right Approach" which promulgates the principle of judging decision and behaviour by their consistency with fundamental personal and group liberties as privileges. This model gives right to employees to criticize the ethics or legality of their employer's actions. Corporate governance norms are also being framed circumventing this ethical model and provides rights/ protection to such person who exposes any kind of information or activity that is deemed illegal, unethical, or not correct within an organization that is either private or public, this is widely known as "whistle blowing policy". The "Justice Model" helps boards and decision making body to judge decision on behaviour by their consistency with an equitable, fair and impartial distribution of benefits (rewards) and costs among individual and groups. The corporate governance norms also promote the decision promoting equitable distribution of benefits. The norms of disclosure help corporates to disclose the key elements like financial position of organisation and salary/benefits of board members through which the prismatic picture is being presented to investors and stakeholders. Protection of minority shareholders through class action suits, establishment of adequate vigil mechanism and to pay sufficient attention to related party transition are included in corporate governance to protect and enrich the trustworthiness. 
All the above ethical models are captured while framing corporate governance model across all nations. These ethical models found their mentioning in Manu-Smriti and Kautilya Arthasastra in one way or the other, wide open to interpretation. It is very difficult to identify one single model as major driving wheel for guiding the leadership of an organization. The corporate governance norms are framed taking key principles of all three models. This can be clearly captured in the following diagram. The ideal model which finds its value in corporate norms lies in between all ethical models as depicted in Figure 1.

Manu-Smriti also elaborates while listing the rules to be followed by the King/ Ruler/ administrator and in current scenario by boards and decision making mechanism, to follow the common good approach which suggests that the interactions with your community are the basis of ethical reasons. The board is continuously answerable to the investors and stakeholders, so they need to follow the path of ethical model implying principle of "common good approach". Manu-Smriti goes ahead and ask leader to respect and compassion for all others especially the vulnerable and similar norms in corporate governance norms prescribes for protecting the interest of minority stakeholders. The virtue approach mentions in Kautilya Arthsastra requires to keep a disposition and habits that enable them to act according to the highest potential of our character. The corporate governance norms mandate the board to follow the transparency and disclosure policy by adhering to the highest level of ethics.

A board faces lots of dilemmas, few of them are captured in pictorial representation (Figure 2) and where they need the yard stick of ethical principles framed in model arrangement of corporate governance principles to sorting out the outcome (Figure 2).

These are the basic building block in framing the corporate "Code of Ethics", through which an organization frames the framework necessary for ethical compliance and promote ethical behaviour within the company and make corporate misbehaviours less likely. The above five bars are driven by principal of ethical compliance which provides the most required way of efficient decision making for boards and governing council. The first bar requires board to ask themselves the question to recognise the

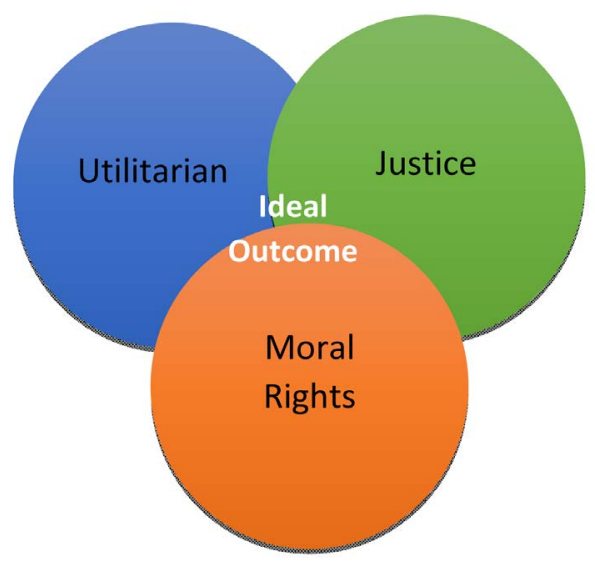

Figure 1. Ideal model for corporate governance in between ethical models. 


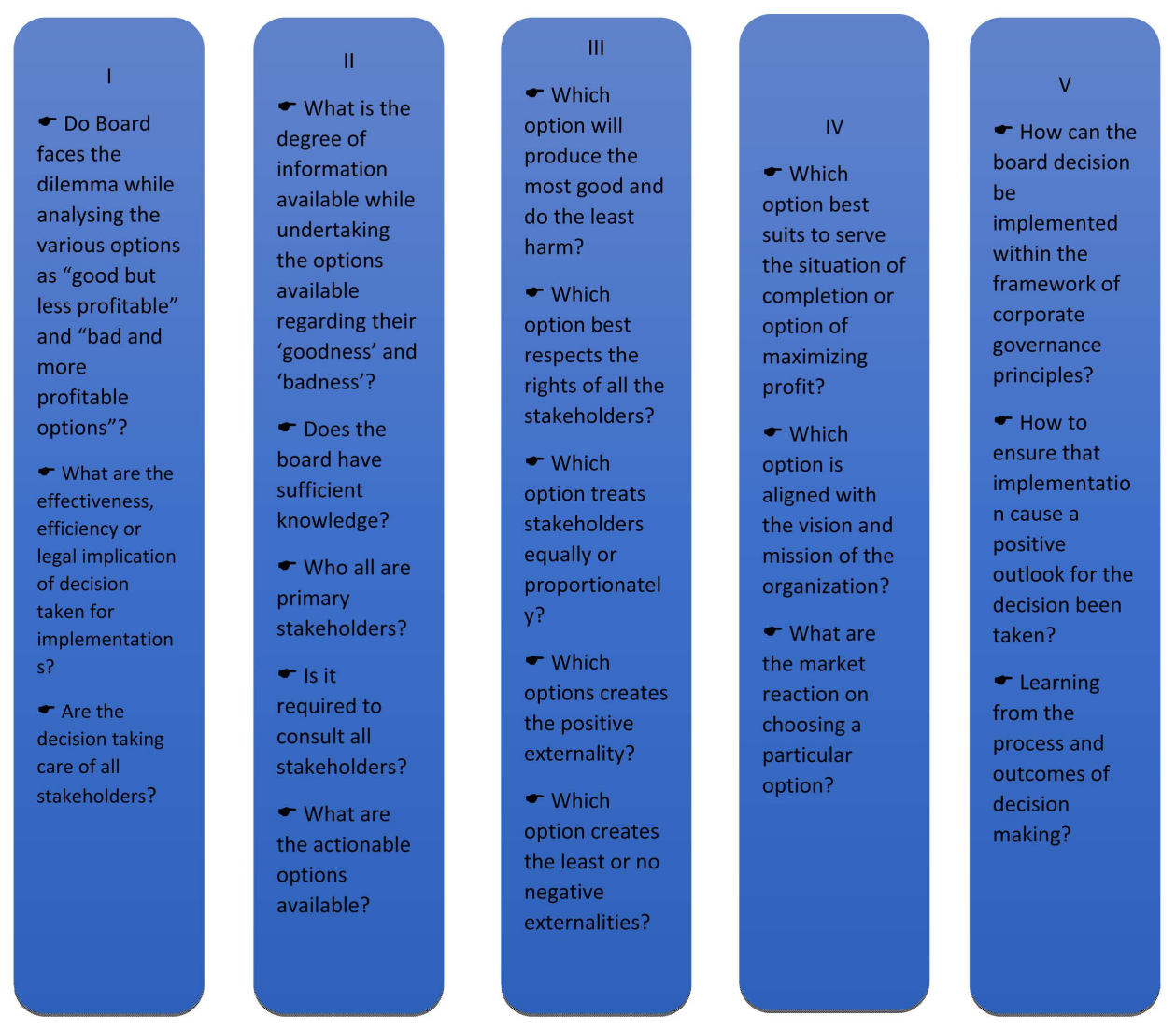

Figure 2. Five bar decision making framework for boards.

Ethical Issue. It depicts the practical dilemma been faced by board while choosing between the two option, one is less profitable but more "good" and another which is more profitable but less "good". Such a scenario, been very common present two polarized paradigms to decision making body. The "shareholder paradigm", where the primary focus is on the maximization of shareholders" wealth, or on a "stakeholder paradigm" where a broader set of issues are presented as appropriate to best practices of corporate governance. This followed by the second bar where the boards or decision bodies strive for establishing the facts while looking thru the various options available. The ethical moral value guides the decision body to follow the most holistic view of "stakeholder paradigm" and find the various alternative been available. The third bar helps in evaluating the alternative options focusing on the "stakeholder paradigm" which is the outcome of deliberation made in framework of ethical responsible business house, followed by the forth bar where the decision is being made. This leads to the final where the outcome of decision made is analysed. This whole process where the central idea is following and adhering to the ethical compliance while taking various decisions helps boards to establish and retain trustworthiness of investors and stakeholders.

Following the Indian Hindu mythology, which stresses on the "purity of motive" principle, business are required to incorporate this principle in their vision and objective statement. The decision body is required to be aware and cautious on this principle and institute a system where the decision made or taken should incorporate the benefits 
of all stakeholders. Kautilya Arthasashtra, emphasizes on keeping two major convictions while performing for the benefits of self and society at large, which is equally valid and applicable for meeting business motives. They are identification of motives in self (for business they and can be correlated to "business ideas") and then framing the ways and means for taking right decision in a particular situation. Lord Krishna also exemplified the same principle while he was exiling Mathura (his kingdom and got his name of Ran-choaar) in between war that the benefits of society is supreme over all materialistic gains. Similar principle is valid for business where they required to think globally about all stakeholders and society at large. Numerous example shows that investors have left discarded where the corruption and unethical behaviour is noticed.

As with any other major civilization whose origins lie in antiquity, one can naturally expect there to be variety of ethical systems within the Indian tradition. Ancient lawmakers brought the notion of dharma (ethics) more down to earth by devising a comprehensive systems of social and moral regulation for each of the different groups, sub groups. This is followed in business environment as well [17]. The makers of Corporate Governance Laws (Government) intended to bring the notion of dharma (ethics) more to the implementation scenario devising the comprehensive system of social and moral regulations for each of the different performing body of business. The most populist tests known as "Dharma Shastra", of which the most relevant are Manu-Smriti and Kautilya Arthasashtra justifies the rigid regime of the "rod" (danda) which is nothing but corporate governance norms, wielded by the king or law body on the grounds that unless there are calculated controls the (natural) law of the small fish (minority stakeholders) being swallowed by the big fish (majority stakeholders) would prevail. Jurisprudence, ordinances for regulating civil life, and the governance and security of the state are the major objectives of ethical compliance.

The various corporate governance theories, in one way or the other stresses on trustworthiness and honesty in all deeds and to be considered as highest virtues of any business establishment [18]. This is because they are crucial to almost any human interchange. Being able to hit a six in game of cricket, or being able to scrutinize a corporate annual report or while taking key decisions in a board room, are much more specific excellence and would usually not to be counted as merely compliance requirement to the ones" duty. Business ethicists and preachers of Corporate Governance Norms, are especially interested in what general traits allow the market to work symphonically in the midst of the larger society [19]. The central idea of cordial social harmony genesis the requirement of Corporate Governance Norms and Ethical compliances.

\section{Conclusions}

Failure in corporate governance is a real threat to the future of every corporation. With efficient practices of Corporate governance, which is entirely embedded and supported within the value framework of core values of integrity and trust equips companies to get an edge in this global competitive market aiming for both organic and inorganic growth in shorter and shorter time, and gain competitive advantage in attracting and 
retaining talent and generating positive reaction in marketplace. Thus, effective corporate governance is directly proportional to adopting set of principles of "Ethical compliance" in every aspect of decision been made and directly translates of success in global volatile market and earning more and more returns to shareholders.

As great deal of adherence to corporate governance practices requires visible examples of fairness, honesty, integrity and the manner board taken decisions. These practices of corporate governance aim at bringing the culture of ethical compliance derived by ancient practices and modern theory and there is great co-relation between the practice and responsible ethical practices and establishing trustworthiness among the stakeholders. The objective of very existence of companies remains same-the "economic growth and returns", but this endeavour of profit making pursuits must limit themselves in the framework of "Ethical Bonding and Compliances". Hence, it is important that the Indian corporates need to regard the concept of Vasudhaiva Kutumbakam as an essential mechanism for their survival and growth in the new economic environment.

This paper has attempted to establish a fact the ancient old Indian doctrine of ManuSmriti and Kautalya Arthashastra, are framed keeping ethical compliance as central and there is great co-relation between modern corporate governance norms and Ethical Behaviour/compliance by Leadership in an Organization.

This understanding from analysis can be further elaborated in following four quadrant model (Table 2) based on analysis which attempts to capture the implication of adherence to Corporate Governance norms and ethical behaviour compliance by leadership in an organization.

Table 2 helps understanding the relationship of high adherence of Corporate Governance Norms and exhibiting high standards of Ethical Behaviour by the decision making body. In these days when corporate governance is emerging as a significant factor, we find that Indian management can emerge successfully in the marketplace if it

Table 2. Quadrant structure for corporate governance norms and ethical behaviour/ compliance by leadership in an organization.

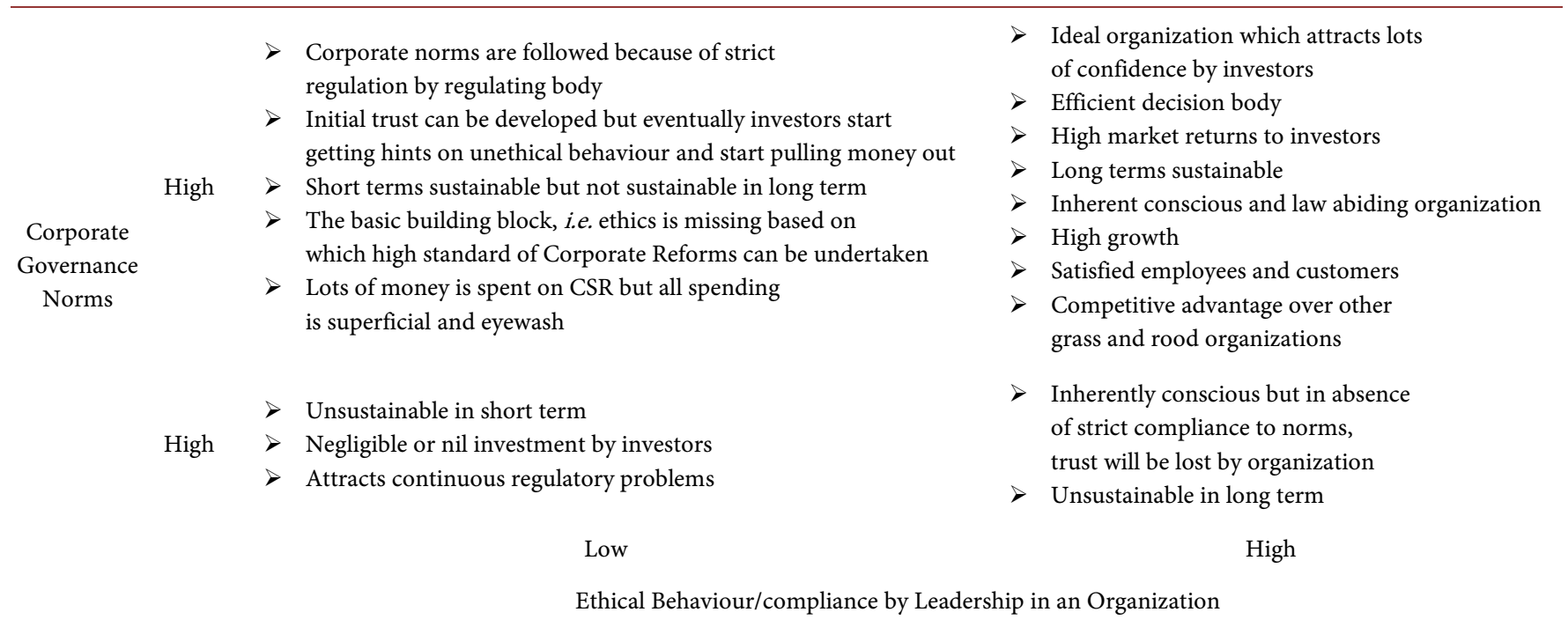


is able to draw on its route for good corporate governance, which is available in our culture and tradition.

\section{Limitation}

The study has been limited to ethical compliance from Indian mythology only and does not cover values derived from any other country. There are many values and ethics which are derived from mythology and can be the genesis of corporate governance framework but the researcher has limited its study on few pertinent values and ethics from Bhagwad Geeta, Manu Smriti and Kautilya Arthasashtra which have been thoroughly discussed. The paper has been limited to the framework of corporate governance and ethical compliance only and has no comparison with any other concept.

As far as the legal part is concerned, that is also limited to legal framework in India with respect to corporate sector. The provisions of Companies Act, 2013 of India have been analysed and no other jurisdictional comparison has been made.

\section{References}

[1] The Maha Upanishad (Sanskrit: महाउपनिषद्, IAST: Mahā Upaniṣad) Is a Sanskrit Text and Is One of the Minor Upanishads of Hinduism.

[2] OECD Principles of Corporate Governance, April 1999. www.oecd.org

[3] Shleifer, A. and Vishny, W. (1986) Large Shareholders and Corporate Control. The Journal of Political Economy, 94, 462.

[4] Brink Alexander, Corporate Governance and Business Ethics: An Introduction, Springer, 2011.

[5] Weiss, J.W. (2009) Business Ethics: A Stakeholder and Issues Management Approach (5th ed.). Cengage Learning India Private Limited.

[6] Weaver, G.R., Trevino, L.K. and Cochran, P.L. (1999) Corporate Ethics Practices in the Mid-1990s: An Empirical Study of the Fortune 1000. Journal of Business Ethics, 18, 283 294. http://dx.doi.org/10.1023/A:1005726901050

[7] Metzger, M., Dalton, D. and Hill, J. The Organization of Ethics and the Ethics of Organizations: The Case for Expanded Organizational Ethics Audit. Business Ethics Quarterly, 3, 27-43. http://dx.doi.org/10.2307/3857380

[8] Paine, L. (1996) Venturing beyond Compliance. The Evolving Role of Ethics in Business, Report No. 1141-96-ch, 13-16, The Conference Board Inc., New York.

[9] Harshbarger, S. and Holden, T. (2004) The New Realities of Corporate Governance. Ethics Matters, Center for Business Ethics, Bentley College.

[10] Van Beek, C. and Solomon, D. (2004) The New Management Dualism: The Power of Ethics in a Global Organization. Ethics Matters, Center for Business Ethics, Bentley College.

[11] Dandino, P. (2004) Corporate Governance: Something for Everyone. Franchising World, 36,41 .

[12] Amato, A.D., Henderson, S. and Florence, S. (2009) Corporate Social Responsibility and Sustainable Business: A Guide to Leadership Tasks and Functions. Center for Creative Leadership, United States.

[13] Nainawat, R. and Meena, R. (2013) Corporate Governance and Business Ethics. Global Journal of Management and Business Studies, 3, 1085-1090. 
[14] Schwartz, M.S., Dunfee, T.W. and Kline, M.J. (2005) Tone at the Top: An Ethics Code for Directors? Journal of Business Ethics, 58, 79. http://dx.doi.org/10.1007/s10551-005-1390-y

[15] Pearce, C.L., Maciariello, J.A. and Yamawaki, H. (2010) The Drucker Difference: What the World's Modern Management through Ancient Indian Wisdom: Towards a More Sustainable Paradigm.

[16] Abugu, J.E. (2011) Directors' Duties and the Frontiers of Corporate Governance. International Company and Commercial Law Review, 22, 322-340.

[17] Chakraborty, S.K. (1997) Business Ethics in India. Journal of Business Ethics, 16, 15291538. http://dx.doi.org/10.1023/A:1005806913385

[18] Bhat, V. (2006-2007) Corporate Governance in India: Past, Present, and Suggestions for the Future. Iowa Law Review, 92, 1431-1435.

[19] Ciulla, J.B. (1991) Why Is Business Talking about Ethics? Reflections on Foreign Conversations. California Management Review, 34, 67-86. http://dx.doi.org/10.2307/41166684

Submit or recommend next manuscript to SCIRP and we will provide best service for you:

Accepting pre-submission inquiries through Email, Facebook, LinkedIn, Twitter, etc. A wide selection of journals (inclusive of 9 subjects, more than 200 journals)

Providing 24-hour high-quality service

User-friendly online submission system

Fair and swift peer-review system

Efficient typesetting and proofreading procedure

Display of the result of downloads and visits, as well as the number of cited articles

Maximum dissemination of your research work

Submit your manuscript at: http://papersubmission.scirp.org/

Or contact tel@scirp.org 